\title{
AN INTEGRATED MODEL OF CORPORATE STRATEGIC ENTREPRENEURSHIP IN SERVICE AND MANUFACTURING CONTEXTS
}

\author{
MARC J. LERCHENMUELLER \\ Yale University \\ New Haven, CT 06520-8034
}

\begin{abstract}
Entrepreneurial action requires a strategic orientation in increasingly turbulent environments. Yet, how orientation leads to action within corporations remains elusive. I posit that entrepreneurial orientation is associated with new venturing and strategic renewal through adaptive or generative searching for opportunities, contingent on differences in service versus manufacturing market needs.
\end{abstract}

\section{INTRODUCTION}

Customers' escalating expectations, new technologies, and global competition increasingly shorten business model lifecycles (Hitt \& Reed, 2000). Corporations must continuously identify new opportunities, while devising strategies for entrepreneurial action in the context in which an opportunity presents itself. Corporate strategic entrepreneurship is at the intersection of these two conditions and is defined as a vision-directed, organization-wide reliance on entrepreneurial behavior that purposefully renews the organization and, or expands the scope if its operations through new venturing (Ireland, Covin, \& Kuratko, 2009). Opportunity identifying behavior is integral to this conception, as the identification of an opportunity represents a preceding necessity to acting on an opportunity, that is, to any new venture being formed or any existing business being renewed to exploit opportunities.

Despite of the apparent importance attributed to distinct elements of corporate strategic entrepreneurship — strategic vision, opportunity identifying behavior, and exploitation — an integrated model has received little attention vis-à-vis research on the constituting elements. For example, more than 100 studies have examined the relationship between strategic vision, commonly assessed as an organization's entrepreneurial orientation, and performance (Rauch, Wiklund, Lumpkin, \& Frese, 2009). Yet, the required entrepreneurial behavior for translating strategic vision into entrepreneurial action remains underexplored (Kollmann \& Stöckmann, 2012). The resulting 'elusiveness of strategic entrepreneurship' leaves ambiguity in the entrepreneurship literature about a promising contributor to competitive advantage (Kuratko \& Audretsch, 2009: 2), and leaves corporations with limited guidance about how to foster entrepreneurship.

In this paper, I draw on the entrepreneurship and marketing literature to develop hypotheses about how entrepreneurial orientation leads to new venturing and strategic renewal. According to the entrepreneurship literature, opportunity identification is $a$ focal entrepreneurial behavior (Shane \& Venkataraman, 2000; Stevenson \& Jarillo, 1990). According to the marketing

literature (Matsuno, Mentzer, \& Özsomer, 2002; Slater \& Narver, 1994), the behavior required to identify opportunities is a function of the market needs a corporation seeks to serve. Market needs encompass expressed yet under-served needs, as well as latent needs that require anticipation of offerings that may satisfy emerging needs in the future (Narver, Slater, \& 
MacLachlan, 2004). Building from these observations, I contrast two behaviors: adaptive searching for opportunities to serve expressed market needs and generative searching for opportunities to meet latent market needs. I posit that adopting an entrepreneurial orientation facilitates both behaviors (based on the entrepreneurship literature), while the relative impact of these behaviors on new venturing and strategic renewal should be contingent on differences in prevailing market needs in a given industry context (based on the marketing literature). I compare service industries that possess unique market characteristics (i.e., product intangibility, greater product uncertainty, and co-production with customers) with manufacturing industries to empirically examine this theoretical contingency in samples of 110 service and 111 manufacturing corporations.

This research contributes to the entrepreneurship literature in several ways. First, it provides a more detailed understanding of corporate strategic entrepreneurship as it integrates constituting elements: entrepreneurial orientation, opportunity identifying behaviors, and opportunity exploitation. Second, it offers insight on how entrepreneurial orientation relates to specific manifestations of opportunity exploitation, new venturing and strategic renewal. Prior work has focused on the relationship between entrepreneurial orientation and generic performance outcomes, like sales growth (Rauch et al., 2009). Third, drawing upon the marketing literature, this research expands insights on opportunity identification as a focal entrepreneurial behavior, contrasting adaptive searching (in the tradition of opportunity discovery) with generative searching (reflecting opportunity creation). The limited application of marketing theory in the entrepreneurship literature has been criticized, especially with respect to theory development on opportunities (Atuahene-Gima \& Ko, 2001; Webb, Ireland, Hitt, Kistruck, \& Tihanyi, 2011). Last, this work offers insight on how industry context, service versus manufacturing, determines the relative importance of adaptive versus generative searching for new venturing and strategic renewal.

\section{THEORY}

Scholars examining the role of strategy for corporate entrepreneurship argue that strategy provides the necessary entrepreneurial orientation towards opportunity exploitation (Ireland et al., 2009). Entrepreneurial orientation is the simultaneous endorsement of innovativeness, proactiveness, and risk taking: Innovativeness refers to endorsing creativity and experimentation; proactiveness is the predisposition toward serving future needs; risk taking is the willingness to act boldly even without knowing all potential consequences (Covin \& Slevin, 1989; Miller, 1983). Entrepreneurial orientation, thus, reflects a disposition toward rather than involvement in entrepreneurial behavior and action (Kollmann \& Stöckmann, 2012). Logically, this orientation is supportive of, but is likely insufficient for the exploitation of opportunities.

I contend that entrepreneurial orientation is associated with opportunity exploitation because it prompts the identification of opportunities. Entrepreneurship scholars discuss a discovery and creation conception of opportunity identification (Alvarez \& Barney, 2013; Shane, 2012). The discovery perspective holds that opportunities result from exogenous, observable shifts in customer needs that are not met by present supply (Kirzner, 1997). The creation perspective views opportunities as endogenously generated by entrepreneurs through experimentation with new or existing offerings in new or existing markets (e.g. Sarasvathy, 2001). The two perspectives differ in the recommended behavior for opportunity identification. Searching for opportunities may have no meaning when opportunities evolve through creation 
rather than exist to be discovered (Alvarez \& Barney, 2007). Yet, some scholars argue (e.g., Zahra, 2008) that some form of searching is likely important to both perspectives.

Building from entrepreneurship scholars' discussion, drawing on the marketing literature, I consider two different types of searching — adaptive and generative - to reflect distinct modes of opportunity identification in the tradition of discovery and creation, respectively. Adaptive searching refers to information gathering about changing needs in the market place (Slater \& Narver, 1994). If according expressed demand is not yet served, it represents an opportunity in the Kirznerian sense of discovery (Kirzner, 1997). Generative searching attempts to unearth and understand latent as opposed to expressed needs. This behavior is distinguished from a mere proactive posture in which an organization is simply highly motivated to realize opportunities for satisfying customers' expressed needs (Narver et al., 2004). Unearthing and understanding latent needs is characteristic entrepreneurial behavior from an opportunity creation perspective.

Entrepreneurial orientation should promote both adaptive and generative searching for opportunities. An entrepreneurial orientation represents a set of expressed intentions aimed at motivating and maintaining coherence between strategic intent and behavior (Atuahene-Gima \& Ko, 2001; Lumpkin \& Dess, 1996). Adaptive searching gathers information about expressed market needs. The expressivity implies, though, that all market participants could gather such information and that benefits are more likely to accrue to those that identify the opportunity early (Kirzner, 1997). For corporations to engage in adaptive searching, it stands to reason that their strategy entails obtaining first mover advantages. Entrepreneurial orientation engenders a willingness to 'beat competitors to the punch' (Miller, 1983: 771), even if it involves taking risks or requires innovative solutions. Innovativeness, proactiveness, and risk-taking are explicitly endorsed under an entrepreneurial orientation, likely promoting adaptive searching.

Generative searching involves unearthing and influencing latent, future needs (Narver et al., 2004). A supportive strategic orientation should be forward-looking with the objective to anticipate new needs. However, future needs are inherently unclear and not immediately observable (Narver \& Slater, 1990). Generative searching therefore also requires a willingness to experiment with novel offerings in service of better understanding these needs. Experimentation not only exposes the corporation to feedback about what features of a new offering may be most valued by the market, it also shapes market needs by exposing the market to new possibilities (Matsuno et al., 2002). Although generative searching may thus inhere a risk reduction aspect, the search is unlikely to result in perfect information about future needs. It is reasonable to expect corporations that are also prepared to take risks to be more likely to search for addressable future needs. Hence, I posit:

\section{Hypothesis 1. Entrepreneurial orientation is positively associated with adaptive searching (1a) and generative searching (1b).}

I propose that opportunity-identifying behavior, in turn, contributes to organizations exploiting opportunities. 'Corporate entrepreneurship has two aims: Establishing new ventures and strategic renewal' (Dess \& Lumpkin, 2005: 147; Guth \& Ginsberg, 1990). New venturing exploits opportunities by entering entirely new markets or expanding operations in existing markets by introducing genuinely novel offerings. Strategic renewal is the revitalization of an organization's operations by changing the scope of its business, its competitive approach, or both (Zahra, 1996). It differs from the related concepts of restructuring or rejuvenation, which are discrete initiatives, by signifying fundamental repositioning efforts in an organization's 
competitive space to exploit opportunities (Simsek \& Heavey, 2011). Thus, new venturing and strategic renewal entail significant resource mobilization. Entrepreneurial orientation directs organizations towards the exploitation of opportunities (Lumpkin \& Dess, 1996). This direction should be transmitted through opportunity-identifying behavior. Stimulated by entrepreneurial orientation, adaptive and generative searching should provide the necessary evidence for forming a new venture or for shaking up existing operations to exploit opportunities.

\section{Adaptive or Generative Searching in Service and Manufacturing Contexts}

The different nature of adaptive and generative searching suggests that their importance for new venturing and strategic renewal may differ contingent on context. Here, context refers to aspects of the environment that shape the motivations, behaviors, and actions of organizations (Zahra, 2008). A fundamental difference lies in the competitive environment faced by service compared to manufacturing organizations. Services are intangible in nature, which should complicate opportunity identification compared to tangible manufactured goods. In services, suppliers and consumers may interpret the importance of service features differently and may even be unable to articulate preferences (Zeithaml, Parasuraman, \& Berry, 1985). Service contexts are uncertain, that is, outcomes of product decisions and the probability of the array of possible outcomes are difficult to assess (Song, Benedetto, \& Zhao, 1999).

To mitigate uncertainty, service organizations are likely to engage in adaptive searching to serve expressed yet neglected market needs (Jaworski \& Kohli, 1993). But because a service is intangible, often only existing in the very moment of purchase, large-scale customer surveys about changes in needs tend to produce inaccurate results (Skaggs \& Youndt, 2004). Searching on a more refined scale, for example asking focus groups about their needs, can yield accurate insights. Such insights, however, may be limited to the customer sample studied or may prove flawed once enacted in an actual commercial setting (Thomke, 2003). Thus, adaptive searching likely produces inaccurate evidence about opportunities in service contexts. When uncertainty is difficult to resolve, organizations are highly receptive to information implicit in the actions of others (Lieberman \& Asaba, 2006), often leading to imitation. Imitating those believed to be more successful or savvy can reduce perceived uncertainty (DiMaggio \& Powell, 1983), subject to imitation being feasible. Since services have characteristically low barriers to entry (compared to more capital-intensive manufacturing) (Song et al., 1999), service firms are particularly vulnerable to imitation. Together, uncertainty and imitability should reduce variation in service organizations' adaptive searching, neutralizing its effect on new venturing and strategic renewal.

Manufacturing organizations produce tangible goods that are more objectively assessable, changing the environment to one more adequately characterized by risk than uncertainty (Matsuno et al., 2002). Organizations can collect information to narrow the range of possible outcomes and assign concomitant probabilities. For example, TATA motors interviewed more than 4,000 truck drivers to conceive their Ace, the first Indian four-wheeler to capture business from three-wheelers (Palepu \& Srinivasan, 2008). This example illustrates that customers tend to be able to articulate needs when products are tangible. Manufacturing further benefits from greater barriers to entry compared to services. Considering the accuracy with which adaptive searching yields information about opportunities, and the lower imitability of resulting offerings, I expect adaptive searching facilitates strategic renewal and new venturing in manufacturing. Extending from Hypothesis 1a (entrepreneurial orientation facilitates adaptive searching), I posit: 


\section{Hypothesis 2. Adaptive searching mediates the relationship between entrepreneurial orientation and new venturing (2a), and entrepreneurial orientation and strategic renewal (2b) in manufacturing industries.}

In contrast, generative searching should mediate the effect of entrepreneurial orientation on new venturing and strategic renewal in manufacturing and services. Generative searching attempts to unearth, understand, and satisfy latent, future market demands (Narver et al., 2004). Identifying an opportunity when customers are largely unaware of the need should require close and continuous customer interconnection to elicit their latent needs. Such interconnection is often characterized by multiple iterations prior to arriving at a new offering that is valued by customers (Narver et al., 2004), a process often found in service industries (Gallouj \& Weinstein, 1997; Kotler, 1983). Generative searching should offer more accurate assessments of needs than adaptive searching in service contexts, providing stronger evidence about opportunities.

Prior research further suggests that interconnectedness gives rise to causal ambiguity, that is, situations where the precise reasons for success or failure when imitating cannot be determined (Szulanski, 1996). For example, consulting firms - offering a knowledge-intensive service - have been able to articulate and meet latent needs by being continuously exposed to the type of problems a customer faces (Bettencourt, Ostrom, Brown, \& Roundtree, 2002). The creation of opportunities to meet latent customer needs is likely a cumulative process that becomes embedded in the interconnection with customers. This embeddedness should erect barriers to entry, which are absent when service organizations engage in adaptive searching. Although close interconnections with customers may be less characteristic of manufacturing industries, generative searching remains a complex, difficult to observe behavior that should cloud cause-effect relationships for outsiders (King, 2007). This should delay investments of rivals and spur opportunity exploitation considering, for instance, how Apple interconnected with more than 200 component suppliers to create an offering (IPhone) that served the unarticulated demand for smartphones while Nokia did not invest and fell behind. The accuracy and excludability with which generative searching identifies opportunities should promote new venturing and strategic renewal in manufacturing and service contexts. Extending from Hypothesis $1 \mathrm{~b}$ (entrepreneurial orientation facilitates generative searching), I posit:

Hypothesis 3. Generative searching mediates the relationship between entrepreneurial orientation and new venturing (3a), and entrepreneurial orientation and strategic renewal (3b) in manufacturing and service industries.

\section{METHODS}

To test the outlined hypotheses, I surveyed American and British corporations in service and manufacturing industries, using a key informant approach targeting one executive per organization. In total, I collected complete survey data on 221 (out of 1,643) organizations, corresponding to a response rate of $13.5 \%$, which is similar to the rate of other surveys of top executives, that is, 10-15\% (Hambrick, Geletkanycz, \& Fredrickson, 1993; Poskela \& Martinsuo, 2009). I used Covin and Slevin's (1989) entrepreneurial orientation scale, and Zahra's (1996) measures of new venturing and strategic renewal. I assessed adaptive and generative search behavior using the established scales by Narver, Slater, and MacLachlan (2004). Confirmatory factor analyses indicated structural validity of all measures. I examined the 
proposed relationships with the organization as the unit of analysis and using partial least squares structural equation models as my samples included less than 250 observations (110 service; 111 manufacturing) (Reinartz, Haenlein, \& Henseler, 2009). Additionally, I used Preacher and Hayes' (2008) ordinary least squares regression technique to assess the posited mediation effects.

\section{RESULTS}

Four partial least squares models were examined to test the outlined hypotheses. The first two models examined mediation of the effect of entrepreneurial orientation on new venturing and strategic renewal through adaptive searching in manufacturing (model 1) and service industries (model 2). Entrepreneurial orientation was positively associated with adaptive searching in both models, that is, across industry contexts, supporting Hypothesis 1a. In turn, adaptive searching was only related to new venturing and strategic renewal in manufacturing industries (model 1), not in services (model 2). Formal tests of mediation, using Preacher and Hayes' regression based procedure, confirmed adaptive searching as mediating the effect of entrepreneurial orientation on new venturing and strategic renewal in manufacturing ( $95 \%$ biascorrected bootstrap confidence interval, $\mathrm{BCCI}_{95 \%}$, of the indirect effect excluded zero), but not in services $\left(\mathrm{BCCI}_{95 \%}\right.$ included zero). Thus, Hypothesis 2 is supported.

The last two models examined mediation of the effect of entrepreneurial orientation on new venturing and strategic renewal through generative searching in manufacturing (model 3) and service industries (model 4). Entrepreneurial orientation was positively associated with generative searching in both models, supporting Hypothesis $1 \mathrm{~b}$. In contrast to adaptive searching, generative searching was positively associated with new venturing and strategic renewal in both manufacturing and service industries. Preacher and Hayes' procedure confirmed mediation of the effect of entrepreneurial orientation on new venturing and strategic renewal through generative searching in manufacturing and services $\left(\mathrm{BCCI}_{95 \%}\right.$ of the indirect effect excluded zero in both samples). Thus, Hypothesis 3 is supported.

\section{CONCLUSION}

This study addresses two open questions in the entrepreneurship literature. First, I identify two possible mechanisms - adaptive and generative searching — by which a corporation's entrepreneurial orientation is associated with opportunity exploitation, manifested in new venturing and strategic renewal. Second, I address the extent to which both search behaviors are important for new venturing and strategic renewal across industry contexts. My results show that while adaptive searching mediates the effect of entrepreneurial orientation on new venturing and strategic renewal only in manufacturing industries, generative searching mediates these relationships in both manufacturing and service industries. These insights provide initial evidence for the complex relationships between the elements to corporate strategic entrepreneurship. Complexities arise not only from the multiple elements-strategic orientation, opportunity identifying behavior, and opportunity exploitation - and their interrelationships, but also across industry contexts. Yet, these complexities are precisely why corporate strategic entrepreneurship is likely a source of competitive advantage in an era of uncertainty and turbulence.

\section{REFERENCES ARE AVAILABLE FROM THE AUTHOR}

